\title{
Fostering Global Science Networks in a Post-COVID-19 World
}

\author{
By Alistair J. Hobday, Carol Robinson, Eugene J. Murphy, Alice Newton, Marion Glaser, and Stephanie Brodie
}

Disruptions to global science networks have followed COVID-19 restrictions. Rather than wait for a return to normal, we propose four areas that can ensure a productive and collaborative future for marine science.

To restrict the spread of COVID-19 disease, regional and national governments have implemented a range of communitybased measures. Physical distancing has closed offices and laboratories, canceled fieldwork and research cruises, and led to scientific productivity declines, notably of female scientists (Staniscuaski et al., 2020; Viglione, 2020; Vincent-Lamarr et al., 2020.) The cessation of international travel was an early measure that looks like it may be continuing for some time.

The resulting shutdown is a shock to scientific endeavors, with jobs lost and funding at risk in many countries. The long-term uncertainty and change will also disrupt international connectivity. Marine science is a global activity as the ocean basins are connected, many species are widely distributed, and human use of the ocean extends far beyond national borders (Ban et al., 2014). As a result, the marine science community has a long history of international collaboration and cooperation fostered through meetings and research relationships developed over many years (Hobday et al., 2017).

A long shutdown will affect groups within the marine science community differently. Senior scientists may find that their established networks are no longer easy to maintain as they deal with the direct and indirect effects of the virus in institutional and national operations. These networks have been crucial in helping early career researchers (ECRs). While many ECRs are building networks using a range of social media platforms, their efforts are not likely to compensate for lost development of trusted networks via international contacts. International movement of ECRs, common between countries for PhD or postdoctoral work, are currently severely restricted, as are peer-to-peer meetings that link ECRs with

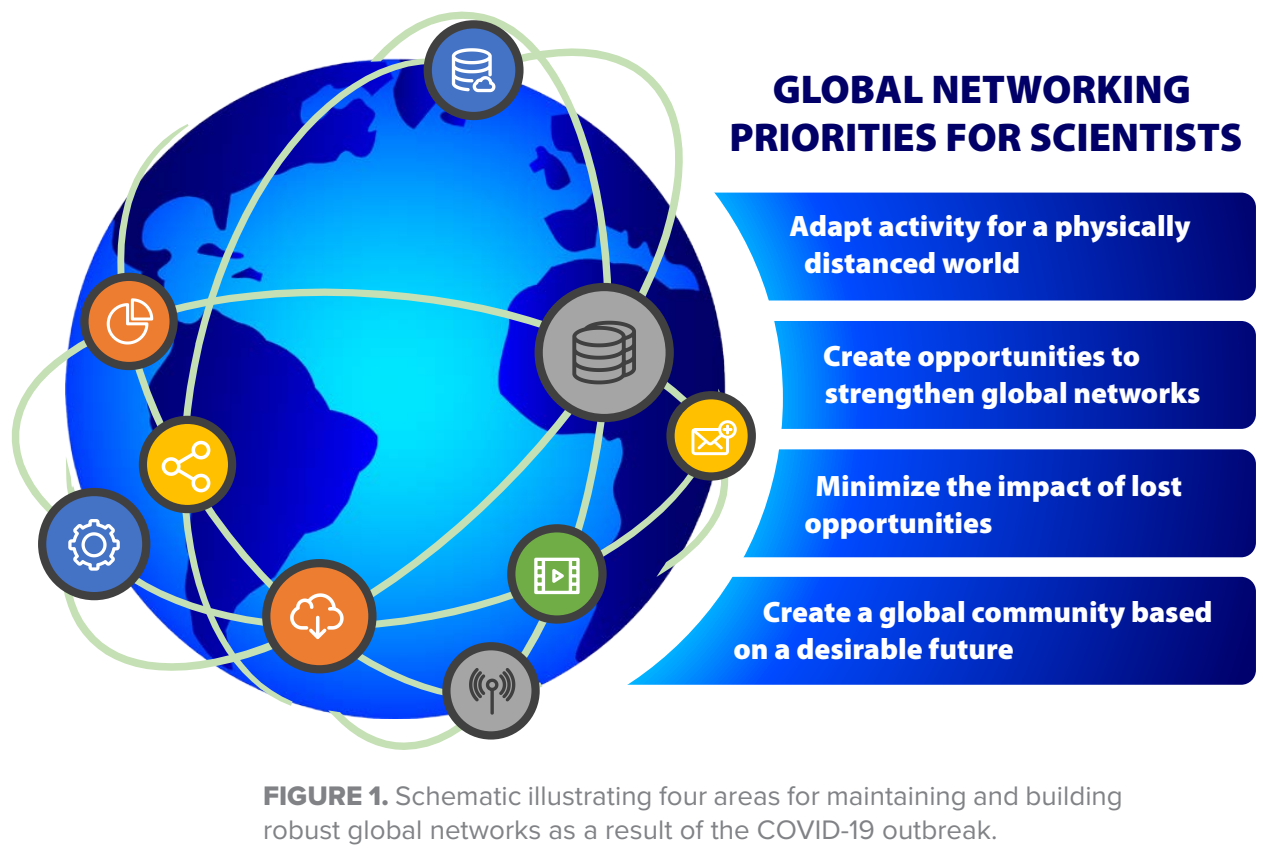

senior scientist networks. International postgraduate programs, such as Erasmus Mundus, ${ }^{1}$ that include mobility to institutions in different countries have halted. Hiring freezes, layoffs, and rising likelihood of funding downturns for years to come will further impede the capacity of ECRs to maintain and pursue careers in STEM (Ahmed et al., 2020; Husby and Modinos, 2020).

Long-term international research societies (e.g., ASLO) and programs (e.g., ICES, SOLAS, IMBeR) have fostered emerging marine scientists with extensive face-to-face activities such as summer schools, early career workshops, and conference sessions that integrate ECRs into the established research community. These types of activities encourage engagement and collaboration with senior scientists-and are one pathway to future employment opportunities. These programs must not wait for a return to normal but must embrace new approaches to support a scientific enterprise that is operating under closed-border and reducedtravel conditions, and that can function in the face of long-term travel restrictions. We propose the following actions to help support a productive and collaborative future for marine science (Figure 1).

\section{Adapt scientific activities for a physically distanced world.}

- Go virtual. While many conferences for 2020 were postponed, others have proceeded with virtual meetings.

- Plan face-to-face national sub-conferences as an enduring replacement for

\footnotetext{
The Erasmus Mundus Joint Master Degree program supports master's degree candidates whose stud ies are conducted in at least two of a long list of subscribing countries (https://ec.europa.eu/programmes/ erasmus-plus/opportunities/individuals/students/ erasmus-mundus-joint-master-degrees_en).
} 
single conference approaches-there will also be carbon benefits (Le Quéré et al., 2020) from reduced travel (Turrell, 2019).

- Embed ECRs in planning, organization, and session chairing of virtual conferences and discussion groups that can thrive in a disrupted world.

- Be innovative with the format of activities in view of virtual meeting fatigue (Robinson and Leach, 2020).

\section{Create opportunities to build and strengthen global networks.}

- Seek and preferentially allocate funding to ECRs to undertake global analyses, supported by senior scientists.

- Establish virtual mentoring schemes, such as pairing ECRs with established scientists in another country or linking international labs to exchange international science culture as well as “just” science.

- Require international working groups to have ECR members.

- Make databases widely available (e.g., Otlet, 2020), and relax restrictions to data access. Build collaborations that increase awareness and use of available data.

\section{Minimize the impact of lost}

\section{opportunities.}

- Petition institutions for policy changes to allow costed and non-costed funding extensions (Robinson and Leach, 2020) for graduate students and postdoctoral researchers, extensions of time-to-degree, and additional support for international ECRs.

- Facilitate cross-national research opportunities; for example, an institution in country A could consider hosting an ECR who, because of COVID-19 restrictions, cannot move to initiate an employment opportunity in country B-this may require new agreements that senior scientists and managers can broker.

- Prioritize travel by ECRs when international restrictions begin to be lifted.

- Allow policy exceptions for institu- tions and research funding that set time limits to being "early career."

\section{Create a global community based on a desirable future.}

- Support senior scientist engagement in ECR mentoring and ECR network development.

- Share educational resources such as online lectures, training materials, and quantitative tutorials. This includes contributing to centralized and searchable metadata nexuses, with links to resources in repositories such as YouTube and Github.

- Sponsor horizon-scanning activities that link ECRs and stakeholders for co-developing priority research questions.

- Use the COVID-19 experience to motivate and maintain a sense of belonging for ECRs (Corbera et al., 2020), particularly those who have always had reduced access to an institutional community. Platforms can be used to document and share experiences related to impacts from COVID-19 (e.g., personal stories, changing ocean use, novel animal behaviors).

COVID-19 restrictions will likely persist for several years. The marine science community must develop innovative ways of compensating for the potential loss of opportunities derived from an active global network of scientists, ranging from assimilating cultural insight gained by working in different countries to learning practical skills in new techniques that are only available in limited locations. Without special effort, we risk breaking international networks and, at the same time, losing a cohort of scientists, impacts that will have a long-lasting detrimental effect on understanding and managing the global ocean. We call on senior leaders and funders of global and regional programs to engage with ECRs and to consider how the needs of both junior and senior scientists can continue to be met in the months and years following this deadly virus outbreak. @

\section{REFERENCES}

Ahmed, M.A., A.H. Behbahani, A. Brückner, C.J. Charpentier, L.H. Morais, S. Mallory, and A.-H. Pool. 2020. The precarious position of postdocs during COVID-19. Science 368(6494):957-958, https://doi.org/ 10.1126/science.abc5143.

Ban, N.C., S.M. Maxwell, D.C. Dunn, A.J. Hobday, N. Bax, J. Ardron, K.M. Gjerde, E.T. Game, R. Devillers, D.M. Kaplan, and others. 2014. Better integration of sectoral planning and management approaches for the interlinked ecology of the open oceans. Marine Policy 49:127-136, https://doi.org/ 10.1016/j.marpol.2013.11.024.

Corbera, E., I. Anguelovski, J. Honey-Rosés, and I. Ruiz-Mallén. 2020. Academia in the time of COVID-19: Towards an ethics of care. Planning Theory \& Practice 21(2):191-199, https://doi.org/ 10.1080/14649357.2020.1757891.

Hobday, A.J., H. Arrizabalaga, K. Evans, K.L. Scales, I. Senina, and K.C. Weng. 2017. International collaboration and comparative research on ocean top predators under CLIOTOP. Deep Sea Research Part // 140:1-8, https://doi.org/10.1016/ j.dsr2.2017.03.008.

Husby, A., and G. Modinos. 2020. Support earlycareer researchers for post-pandemic prospects. Nature 580:185, https://doi.org/10.1038/ d41586-020-01031-2.

Le Quéré, C., R.B. Jackson, M.W. Jones, A.J.P. Smith, S. Abernethy, R.M. Andrew, A.J. De-Gol, D.R. Willis, Y. Shan, J.G. Canadell, and others. 2020. Temporary reduction in daily global $\mathrm{CO}_{2}$ emissions during the COVID-19 forced confinement. Nature Climate Change 10:647-653, https://doi.org/ 10.1038/s41558-020-0797-x.

Otlet. 2020. Global open-access platform to share and source biological samples, https://otlet.io/about-us.

Robinson, S., and J. Leach. 2020. Here is why

you might be feeling tired while on lockdown. The Conversation, April 6, 2020, https://theconversation.com/here-is-why-you-mightbe-feeling-tired-while-on-lockdown-135502.

Staniscuaski, F., F. Reichert, F.P. Werneck, L. de Oliveira, P.B. Mello-Carpes, R.C. Soletti, C.I. Almeida, E. Zandona, F.K. Ricachenevsky, A. Neumann, and others. 2020. Impact of COVID-19 on academic mothers. Science 368(6492):724, https://doi.org/10.1126/science.abc2740.

Turrell, W.R. 2019. Marine science within a net-zero emission statutory framework. ICES Journal of Marine Science, https://doi.org/10.1093/icesjms/ fsz164.

Viglione, G. 2020. Are women publishing less during the pandemic? Here's what the data say. Nature 581:365-366, https://doi.org/10.1038/ d41586-020-01294-9.

Vincent-Lamarr, P., C.R. Sugimoto, and V. Larivière. 2020. The decline of women's research production during the coronavirus pandemic. May 19, 2020, https://www.natureindex.com/news-blog/ decline-women-scientist-research-publishingproduction-coronavirus-pandemic.

\section{AUTHORS}

Alistair J. Hobday (alistair.hobday@csiro.au) is Research Director \& Senior Principal Research Scientist, CSIRO Oceans and Atmosphere, Hobart, Tasmania, Australia. Carol Robinson is Professor of Marine Sciences, Centre for Ocean and Atmospheric Sciences, School of Environmental Sciences, University of East Anglia, Norwich, Norfolk, UK. Eugene J. Murphy is Science Leader of the Ecosystems Programme, British Antarctic Survey, Cambridge, UK. Alice Newton is Professor, Marine and Environmental Research Center (CIMA), University of Algarve, Faro, Portugal. Marion Glaser is Work Group Leader, Leibniz Centre for Tropical Marine Research (ZMT), Bremen, Germany. Stephanie Brodie is Assistant Project Scientist, Institute of Marine Science, University of California, Santa Cruz, CA, USA. 